\title{
Cyclical Variations in the Performance of Exchange-traded Funds
}

\author{
Yao Zheng ${ }^{1} \&$ Eric Osmer ${ }^{1}$ \\ ${ }^{1}$ College of Business, University of New Orleans, New Orleans, LA, USA \\ Correspondence: Yao Zheng, College of Business, University of New Orleans, 2000 Lakeshore Drive, New \\ Orleans, LA 70148, USA. Tel: 1-504-460-1768. E-mail: yzheng3@uno.edu
}

$\begin{array}{lc}\text { Received: July 1, 2012 } & \text { Accepted: September 11,2012 Online Published: September 14, } 2012 \\ \text { doi:10.5539/ijef.v4n11p15 } & \text { URL: http://dx.doi.org/10.5539/ijef.v4n11p15 }\end{array}$

\begin{abstract}
This paper investigates the link between exchange-traded funds (ETFs) and the macroeconomy. Using a nonlinear approach, we find that the one-month T-bill rate, default risk premium, change in the money supply, growth of industrial production, and dividend yield have predictive power with regards to the return on ETFs. Moreover, the predictive power of these macro variables depends both on the underlying volatility state as well as the focus of the ETF. Additionally, our evidence suggests that ETFs have asymmetric risk exposure across expansion and recession states.
\end{abstract}

Keywords: business fluctuations, cycles, exchange-traded funds, Markov regime-switching, financial forecasting

JEL Classification Code: G10, G14, E32, E37

\section{Introduction}

Exchange-traded funds, or ETFs, are investment instruments that trade like stocks on a stock exchange. Over the past decade they have gained increasing popularity due to the fact they offer investors a number of benefits such as lower costs, trading flexibility, tax efficiency, transparency, and exposure to a variety of markets. Although ETFs are currently a sought-after instrument for investors, they do not receive enough attention from academia. In particular, there are few studies that focus on how changes in the macroeconomy impact the performance of ETFs. In this study, we examine the time variation of ETF performance using a two-regime Markov-switching model incorporating time varying regime-switching probabilities. This framework is helpful in that it allows for the intercept, coefficients, and residual volatility to change with our state variable in a latent approach. Empirical results suggest that when there are high conditional volatilities, the performance of ETFs is more sensitive to changes in the factors that have predictive power of future economic conditions and that ETFs have asymmetric risk exposure across expansion and recession states.

The remainder of this study is structured as follow. Section 2 reviews past literature. Section 3 examines our basic econometric framework. Section 4 looks at data and variables used for the paper and Section 5 presents the model specifications and empirical results. The last section concludes the study and makes suggestions for future research.

\section{Past Literature and Motivation}

Although there is a growing body of literature on ETFs, most studies tend to focus on pricing (Ackert and Tian, 2008; Engle and Sarkar, 2002; Lin, Chan, and Hsu, 2006; Jares and Lavin, 2004), market efficiency and overreaction (Madura and Richie, 2004; Cherry, 2004), tax efficiency (Poterba and Shoven, 2002), or performance and trading characteristics (Dellva, 2001; Kostovetsky, 2003; Gallagher and Segara, 2005). Rarely are there studies looking at the link between the returns of ETFs and the state of economy. This is somewhat surprising since the performance of ETFs has been greatly impacted both by the 2000 Dot-com Bubble and the 2008 Financial Crisis. It is these recent changes to the economy that motivate us to study whether variables related to the macroeconomy can predict the performance of ETFs. Therefore, our study can be said to differentiate from past literature in that it is the first to focus on the variations of the predictive power macro variables have on the performance of ETFs across expansions and recessions. To capture different aspects of the underlying economy, the following variables are chosen: the one-month T-bill rate, default risk premium, change in the money supply, growth of industrial production, and dividend yield. Since changes in the underlying economic conditions may have different impacts on ETFs with different focuses we therefore study the 
following five representative groups of ETFs: finance, health, real estate, technology, and utilities. This allows us to extract different reactions to changes in the economy from ETFs with different foci.

Our goal is to develop a nonlinear model that investigates the relation between the previously listed macro factors and the performance of ETFs. By incorporating the one-month T-bill rate into the regime switching probabilities, we are able to extract the cyclical variations in the predictive power of these macro variables. Our work mostly follows Gulen, Xing, and Zhang (2011) (Note 1) Perez-Quiros and Timmermann (2000) (Note 2). Our results indicate that the one-month T-bill rate, default risk premium, change in the money supply, growth of industrial production, and dividend yield have predictive power for the return on exchange-traded funds. The predictive power of these macro variables depends both on the underlying volatility state and the focus of the ETF. Additionally, our evidence suggests that ETFs have asymmetric risk exposure across expansion and recession states.

\section{General Framework}

A potentially useful approach to modeling nonlinearities in time series is to assume different behavior in different regimes. If the dates in which the regime switches have taken place are known, then modeling can be estimated simply by using dummy variables. However, since the prevailing regime is not always directly observable a Markov-switching framework is preferable. It is a latent state approach that does not require the conditioning on predefined state indicators. The state transition probability obtained through this estimation reveals valuable information regarding the movements of changes in the conditional distribution of the ETFs returns. Following Gulen, Xing and Zhang (2011) and Perez-Quiros and Timmermann (2000), we adopt the following econometric framework.

Let $r_{t}$ denote ETF excess return in month $t$ (in excess of one month T-bill rate) and $X_{t}$ denote a set of conditioning factors used to explain the excess return $r_{t}$. The regime-switching specification follows a generalized framework and allows the intercept, coefficients, and variance to depend on a latent state variable, $S_{t}$ :

$$
r_{t}=\alpha_{S_{t}}+\beta_{S_{t}}^{\prime} X_{t}+\varepsilon_{t} \quad \text { with } \quad \varepsilon_{t} \sim N\left(0, \sigma_{S_{t}}^{2}\right),
$$

in which $N\left(0, \sigma_{S}^{2}\right)$ is normally distributed with zero mean and a variance of $\sigma_{S}^{2}$. We allow the parameters to differ across two states. This methodology allows for the interpretation of the nature of the state from the data without presumption or restrictions. The regression coefficients and variance are either $\left(\alpha_{1}, \beta_{1}^{\prime}, \sigma_{1}^{2}\right)$ or $\left(\alpha_{2}, \beta_{2}^{\prime}, \sigma_{21}^{2}\right)$, depending on the state.

Next, we specify the state transition probabilities as following:

$$
\begin{aligned}
& p_{t}=P\left(S_{t}=1 \mid S_{t-1}=1, Y_{t-1}\right)=p\left(Y_{t-1}\right) \\
& 1-p_{t}=P\left(S_{t}=2 \mid S_{t-1}=1, Y_{t-1}\right)=1-p\left(Y_{t-1}\right) \\
& q_{t}=P\left(S_{t}=2 \mid S_{t-1}=2, Y_{t-1}\right)=q\left(Y_{t-1}\right) \\
& 1-q_{t}=P\left(S_{t}=1 \mid S_{t-1}=2, Y_{t-1}\right)=1-q\left(Y_{t-1}\right)
\end{aligned}
$$

in which $Y_{t-1}$ is a vector of variables containing information that is available to public at $t-1$ and affects the regime-switching probabilities between $t$ - 1 and $t$. Traditional formulations of Markov-switching models generally make assumptions that there are constant state transition probabilities. However, recent literature suggests that the these transition probabilities are time varying and are based on prior information such as interest rates (Gray, (1996), and Gulen et al, (2004)) or some other macro factors variables. By incorporating time-varying transition probabilities, one is able to observe important economic behavior that may be neglected by assuming transition probabilities are constant

We obtain these parameters from the model through MLE (Note 3), with some assumptions made regarding the conditional density function of the innovation $\varepsilon_{t} \varepsilon_{t} \sim N\left(0, \sigma_{S_{t}}^{2}\right)$. The vector of parameters joining the likelihood function from the sample data is represented by $\theta$. Assume that the density of the of the innovations, $\varepsilon_{t}$ that conditional on state $j, f\left(r_{t} \mid S_{t}=j, X_{t} ; \theta\right)$, is Gaussian: 


$$
f\left(r_{t} \mid \Omega_{t-1}, S_{t}=j, X_{t} ; \theta\right)=\frac{1}{\sqrt{2 \pi \sigma_{j}}} \exp \left(\frac{-\left(r_{t}-\alpha_{j}-\beta_{j}^{\prime} X_{t}\right)^{2}}{2 \sigma_{j}}\right)
$$

for $j=1,2, \Omega_{t-1}$ denotes the information set $X_{t-1}, r_{t-1}, Y_{t-1}$, and also their lagged value. We assume that the relationship between, $X_{t}$ and $r_{t}$ is constant within every state, but allow for these coefficients varying between the states. Therefore, our log-likelihood function is given by:

$$
L\left(r_{t} \mid \Omega_{t-1} ; \theta\right)=\sum_{t=1}^{T} \log \left(\phi\left(r_{t} \mid \Omega_{t-1} ; \theta\right)\right)
$$

where the density, $\phi\left(r_{t} \mid \Omega_{t-1} ; \theta\right)$, is calculated as the sum of the probability-weighted state densities, $f(\bullet)$ across two potential states:

$$
\phi\left(r_{t} \mid \Omega_{t-1} ; \theta\right)=\sum_{j=1}^{2} f\left(r_{t} \mid \Omega_{t-1}, S_{t}=j ; \theta\right) P\left(S_{t}=j \mid \Omega_{t-1} ; \theta\right),
$$

and $P\left(S_{t}=j \mid \Omega_{t-1} ; \theta\right)$ is the conditional probability of state $j$ at time $t$ given information at time $t-1$. The conditional transition probabilities reflect the investors' beliefs of the following period being the high volatility state.

We then obtain the conditional state probabilities recursively based on the total probability theorem:

$$
P\left(S_{t}=i \mid \Omega_{t-1} ; \theta\right)=\sum_{j=1}^{2} P\left(S_{t}=i \mid S_{t-1}=j, \Omega_{t-1} ; \theta\right) P\left(S_{t-1}=j \mid \Omega_{t-1} ; \theta\right),
$$

Then, using Bayes' rule, we obtain the conditional state probabilities as following:

$$
\begin{aligned}
P\left(S_{t-1}=j \mid \Omega_{t-1} ; \theta\right) & =P\left(S_{t-1}=j \mid r_{t-1}, X_{t-1}, Y_{t-1}, \Omega_{t-2} ; \theta\right) \\
& =\frac{f\left(r_{t-1} \mid S_{t-1}=j, X_{t-1}, Y_{t-1}, \Omega_{t-2} ; \theta\right) P\left(S_{t-1}=j \mid X_{t-1}, Y_{t-1}, \Omega_{t-2} ; \theta\right)}{\sum_{j=1}^{2} f\left(r_{t-1} \mid S_{t-1}=j, X_{t-1}, Y_{t-1}, \Omega_{t-2} ; \theta\right) P\left(S_{t-1}=j \mid X_{t-1}, Y_{t-1}, \Omega_{t-2} ; \theta\right)} .
\end{aligned}
$$

We then iterate the last two equations recursively to obtain the state transition probabilities and derive the parameter estimates of the likelihood function. Therefore, the variation in the distribution of excess returns conditional on the included regressors drives the inferred state probabilities.

\section{Data}

The return data for the exchange-traded funds spans from January 2001 to December 2010 covering ETFs with an investment focus on the financial industry, the health industry, real estate industry, technology industry, and utility industry. We then create five equally weighted portfolios containing all the ETFs with the same investment focus. To be included in our sample, the ETFs have to satisfy the following criterion: (1) listed on NYSE Arca, (2) have at least two years of data and (3) have an investment focus from one of the five previously listed industries. The data is collected from the Yahoo Finance ETF Center (Note 4).

Table 1. Summary Statistics

\begin{tabular}{lccccc}
\hline & Finance ETFs & Health ETFs & Real Estate ETFs & Technology ETFs & Utilities ETFs \\
\hline Mean & -0.0019 & 0.0023 & 0.0022 & 0.0027 & 0.0026 \\
Median & 0.0080 & 0.0041 & 0.0067 & 0.0062 & 0.0114 \\
Standard Deviation & 0.0814 & 0.0457 & 0.0695 & 0.0868 & 0.0450 \\
Minimum & -0.3193 & -0.1516 & -0.3021 & -0.2624 & -0.1393 \\
Maximum & 0.2371 & 0.1063 & 0.2812 & 0.2314 & 0.1027 \\
Kurtosis & 3.6145 & 0.7702 & 5.3336 & 0.7026 & 1.0517 \\
Skewness & -1.0384 & -0.4450 & -0.8389 & -0.2534 & -0.8980 \\
\hline
\end{tabular}

\footnotetext{
This table contains the descriptive statistics for the returns on the five groups of ETFs.
} 
The summary statistics of the returns for the five groups of ETFs are provided in Table 1. The average return for ETFs with a focus on the financial industry is the lowest among the five groups with monthly average return of $-0.19 \%$ and a standard deviation of $8.4 \%$. In contrast, the average return for ETFs with a focus on the technology industry is the highest among the five groups. Its monthly average return is $0.27 \%$ with a standard deviation of $8.68 \%$. The low average return for finance ETFs is likely due to how hard the financial industry was hit during the 2008 Financial Crisis. However, the relatively high return for the technology ETFs is likely due to the rapid growth the technology industry experienced after the 2000 Dot-com Bubble. The average return for ETFs with a focus on the health industry, real estate industry, and utility industry are $0.22 \%, 0.23 \%$, and $0.26 \%$ per month, respectively. Figure 1 plots the average returns for the five groups of ETFs. We also overlay these returns with historical NBER recession dates.
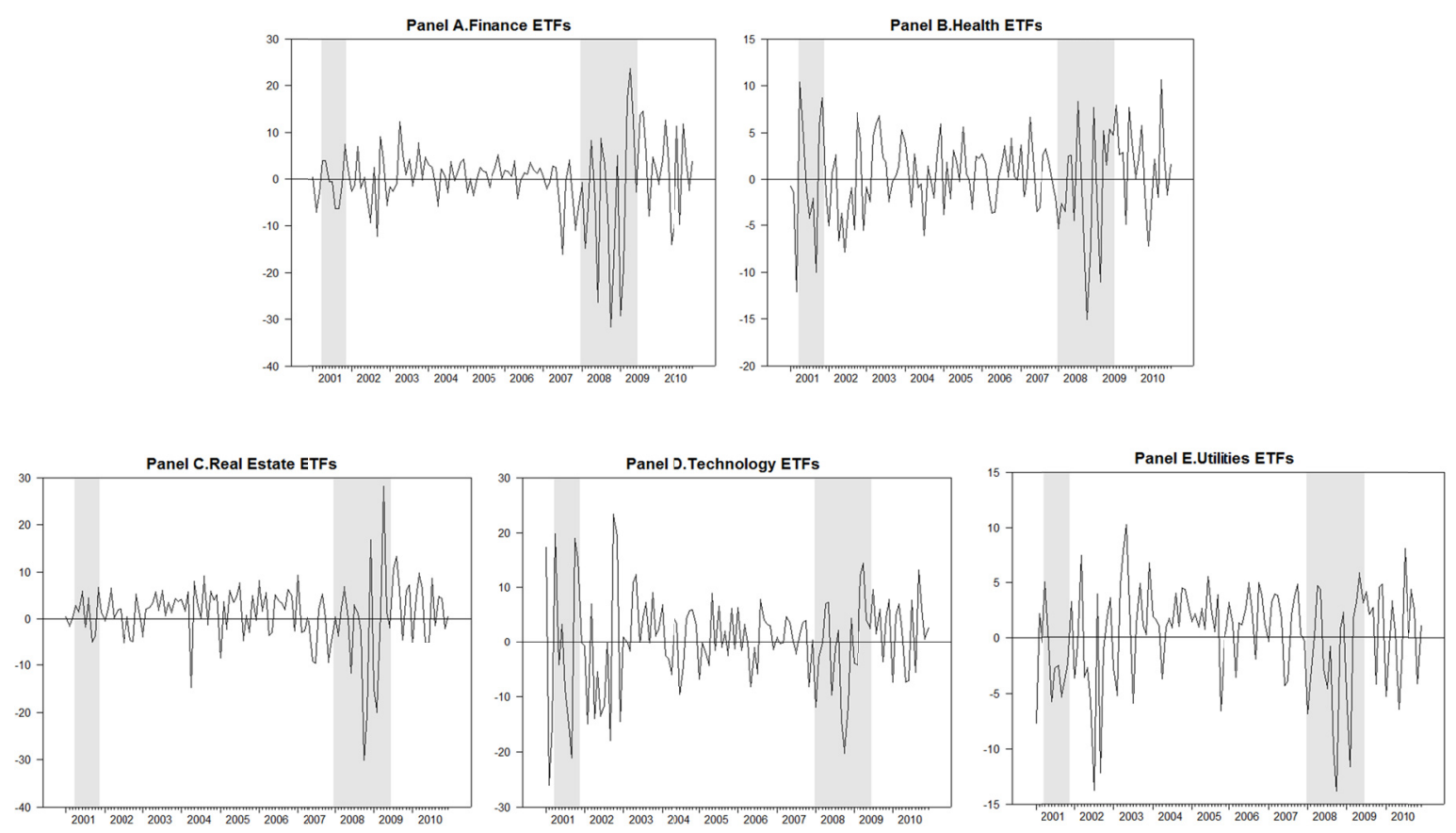

Figure 1. Returns of ETFs

This figure contains time series plots of monthly average returns for ETFs with focus in financial industry, health industry, Real Estate, Technology, and Utilities. Shadows are NBER recessions.

Table 2 analyses the correlations of the returns for the five groups of ETFs. Among the five groups the correlation between ETFs with a focus on the financial industry and ETFs with a focus on the real estate industry is the highest -0.80 . The higher correlation is largely consistent with what we see for the 2007-2008 Financial Crisis. During that time period the housing market and the financial industry go through decline and collapse. The housing bubble in the U.S. burst in 2007 causing the value of securities backed by real estate assets to plummet, thus resulting in heavy damage to financial institutions. In contrast, ETFs with a focus on technology and ETFs with a focus on utilities have the least correlation with each other -0.43 .

Table 2. Correlation Matrix

\begin{tabular}{llllll}
\hline & Finance ETFs & Health ETFs & Real Estate ETFs & Technology ETFs & Utilities ETFs \\
\hline Finance ETFs & 1.0000 & 0.6668 & 0.7972 & 0.6129 & 0.5620 \\
Health ETFs & & 1.0000 & 0.5559 & 0.7160 & 0.5815 \\
Real Estate ETFs & & & 1.0000 & 0.4602 & 0.5278 \\
Technology ETFs & & & 1.0000 & 0.4346 \\
Utilities ETFs & & & & & 1.0000 \\
\hline
\end{tabular}

This table lists the correlation matrix of the five groups of ETFs. 
We then model the excess return of ETFs using the following lagged variables: one-month T-bill rate, the default risk premium, the change in the money supply, the change in the growth rate of industrial production, as well as the dividend yield. The one-month T-bill rate is a variable commonly used to predict stock market returns as discussed in previous literature. The default risk premium is the difference of two corporate bonds yields: Moody's Baa and Aaa. Past literature shows that the default spread is a strong indicator in the forecasting of business cycles. Fama and French (1989) also use the default spread as an important conditional variable to predict stock returns. We capture changes in aggregate liquidity by using the change in the money supply, which is calculated as the twelve-month log difference in the money stock. This variable can also capture shocks from monetary policy that impact underlying macroeconomy. Our fourth variable is the change in industrial production growth rate, which is calculated as the twelve-month log difference of the Industrial Production index Last, the dividend yield is calculated as the dividends on the CRSP (Note 5) value-weighted market portfolio from the past twelve-months divided by the price of the stock at the end of the month. This variable is also standard in past literature because it reflects mean reversion in expected returns. The economic intuition is that a large dividend yield implies that a higher rate is used to discount dividends. The data for the five variables is obtained through the Federal Reserve, except for dividend yield which is calculated from CRSP data.

\section{Model Specification and Empirical Results}

In this section, we first provide specification in extension to a general econometric framework. Then we provide empirical analysis of this specified model.

\subsection{Model Specification}

For each group of ETFs, denoted by $i$, we estimate model below:

$$
\begin{aligned}
& r_{t}^{i}=\beta_{0, S_{t}}+\beta_{1, S_{t}} T B_{t-1}+\beta_{2, S_{t}} D E F_{t-1}+\beta_{3, S_{t}} \Delta M_{t-2}+\beta_{4, S_{t}} \Delta I P_{t-1}++\beta_{5, S_{t}} D I V_{t-1}+\varepsilon_{t}^{i} \\
& \varepsilon_{t}^{i} \sim N\left(0, \sigma_{i, S_{t}}^{2}\right), \quad S_{t}=\{1,2\}
\end{aligned}
$$

where $r_{t}^{i}$ is equally weighted excess return (monthly) for the $i$ th group of ETFs, TB, DEF, $\triangle M, \triangle I P$, and $D I V$ which denote the one-month T-bill rate, the default risk premium, the changes in the money supply, the change in the industrial production growth rate, as well as the dividend yield, respectively. Following Perez-Quiros and Timmermann (2000) and Gulen et el (2011) framework, , we choose a lag of one month for the change in industrial production growth rate, the dividend yield, the one-month T-bill rate, and the default spread, but a lag of two months for the growth in money supply. The two month lag allows for the publication delay of the money supply data.

We allow the state dependence for the conditional variance, $\sigma_{S_{t}}^{2}$. To model investors' conditional beliefs, we follow Gray (1996) and Gulen, Xing and Zheng (2011) and incorporate the regime-switching probabilities as a linear function of one-month T-bill rate. In this manner, we are able to extract the information currently known to the public regarding conditions of macroeconomy in the future. To be specific, these probabilities are denoted as:

$$
\begin{aligned}
& p_{t}^{i}=P\left(S_{t}^{i}=1 \mid S_{t-1}^{i}=1, Y_{t-1}\right)=\Phi\left(\mu_{0}^{i}+\mu_{1}^{i} T B_{t-1}\right) \\
& 1-p_{t}^{i}=P\left(S_{t}^{i}=2 \mid S_{t-1}^{i}=1\right) ; \\
& q_{t}^{i}=P\left(S_{t}^{i}=2 \mid S_{t-1}^{i}=2, Y_{t-1}\right)=\Phi\left(\mu_{0}^{i}+\mu_{2}^{i} T B_{t-1}\right) ; \\
& 1-q_{t}^{i}=P\left(S_{t}^{i}=2 \mid S_{t-1}^{i}=2\right) ;
\end{aligned}
$$

in which $S_{t}^{i}$ indicates the state for $i$ th fund and $\Phi$ denotes the cumulative density function of a standard normal variable. This specification is similar to Gray (1996). We extract investors' information on regime-switching probabilities parsimoniously by using risk free rate. The model is estimated using maximum likelihood estimation.

\subsection{Empirical Results}

Table 3 suggests that high conditional volatilities often occur in state 1 and low conditional volatilities often occur in state 2 . Therefore, state 1 is identified as the high volatility regime/state and state 2 is identified as the 
low volatility regime/state. For the five groups of ETFs the differences in volatilities across states 1 and 2 are similar in magnitude.

Table 3. Regime-Switching Regressions of Macro Variables

\begin{tabular}{|c|c|c|c|c|c|c|c|c|c|c|}
\hline \multirow[b]{2}{*}{ Intercept, $\mathrm{St}=1$} & \multicolumn{2}{|c|}{ Finance ETFs } & \multicolumn{2}{|c|}{ Health ETFs } & \multicolumn{2}{|c|}{ Real Estate ETFs } & \multicolumn{2}{|c|}{ Technology ETFs } & \multicolumn{2}{|c|}{ Utility ETFS } \\
\hline & $0.13^{* * *}$ & $(0.03)$ & 0.006 & $(0.01)$ & 0.09 & $(0.47)$ & -0.06 & $(0.09)$ & 0.04 & $(0.03)$ \\
\hline Intercept, $\mathrm{St}=2$ & $-0.10^{* * *}$ & $(0.01)$ & $-0.17^{* * *}$ & $(0.00)$ & $0.03^{* * *}$ & $(0.01)$ & -0.08 & $(0.05)$ & $0.02^{* * *}$ & $(0.00)$ \\
\hline $\mathrm{TB}, \mathrm{St}=1$ & $-26.21^{* * *}$ & $(8.78)$ & $-18.38^{* * *}$ & $(3.10)$ & -20.55 & $(4.42)$ & -16.37 & (7.42) & $-11.39^{* *}$ & (4.76) \\
\hline $\mathrm{TB}, \mathrm{St}=2$ & -1.63 & $(2.47)$ & $-11.17^{* * *}$ & (1.39) & -4.64 & $(3.13)$ & -4.01 & $(4.22)$ & -1.41 & (1.23) \\
\hline $\mathrm{DEF}, \mathrm{St}=1$ & $9.68^{* * *}$ & $(1.50)$ & $4.67^{* * *}$ & $(0.43)$ & $8.19^{* * *}$ & $(8.61)$ & $8.010^{*}$ & $(4.79)$ & $4.19^{* * *}$ & $(0.56)$ \\
\hline $\mathrm{DEF}, \mathrm{St}=2$ & $3.82^{* *}$ & $(1.58)$ & $8.3^{* * *}$ & $(0.45)$ & -2.42 & $(1.97)$ & $2.66^{*}$ & $(2.82)$ & $1.19^{* * *}$ & (1.05) \\
\hline$\Delta \mathrm{M}, \mathrm{St}=1$ & -0.02 & $(0.15)$ & $0.10^{* *}$ & $(0.05)$ & $7.89^{* * *}$ & $(0.53)$ & -0.07 & $(0.38)$ & -0.03 & $(0.10)$ \\
\hline$\Delta \mathrm{M}, \mathrm{St}=2$ & 0.11 & $(0.08)$ & $-1.69^{* * *}$ & $(0.23)$ & $0.18^{* *}$ & $(0.09)$ & $-0.15^{* *}$ & $(0.16)$ & -0.03 & $(0.04)$ \\
\hline$\Delta \mathrm{IP}, \mathrm{St}=1$ & $-5.93^{*}$ & $(2.61)$ & $-2.32^{*}$ & $(1.20)$ & -6.81 & (9.89) & 0.76 & $(4.46)$ & -0.86 & (1.72) \\
\hline$\Delta \mathrm{IP}, \mathrm{St}=2$ & 1.13 & $(1.52)$ & -1.16 & $(1.28)$ & 0.29 & $(1.62)$ & -2.20 & $(2.47)$ & 0.93 & (1.14) \\
\hline $\mathrm{DIV}, \mathrm{St}=1$ & -0.22 & (1.15) & $2.87^{* * *}$ & $(0.32)$ & -11.44 & (14.64) & $9.52^{* * *}$ & $(1.43)$ & $0.80^{* * *}$ & (1.27) \\
\hline DIV, $\mathrm{St}=2$ & $4.21^{* * *}$ & $(0.51)$ & $9.23^{* * *}$ & $(0.22)$ & 0.60 & $(0.78)$ & $4.43^{* * *}$ & (3.33) & -0.04 & $(0.43)$ \\
\hline \multicolumn{11}{|c|}{ Trans. Prob. Parameters } \\
\hline Constant & $0.70^{* *}$ & $(0.35)$ & $2.05^{* * *}$ & $(0.38)$ & $1.56^{* * *}$ & $(0.43)$ & $1.37^{* *}$ & $(0.56)$ & 0.50 & $(0.43)$ \\
\hline $\mathrm{TB}, \mathrm{St}=1$ & 3.40 & $(2.57)$ & 1.63 & $(4.07)$ & 0.13 & $(0.40)$ & 4.40 & $(3.73)$ & 0.24 & (1.57) \\
\hline $\mathrm{TB}, \mathrm{St}=2$ & $2.91^{* *}$ & $(1.37)$ & -0.32 & $(1.26)$ & 5.44 & $(4.74)$ & 1.93 & (2.14) & 0.83 & (1.42) \\
\hline \multicolumn{11}{|l|}{ Stand. Dev. } \\
\hline$\sigma, \mathrm{St}=1$ & $0.09^{* * *}$ & $(0.01)$ & $0.05^{* * *}$ & $(0.01)$ & $0.08^{* * *}$ & $(0.02)$ & $0.11^{* * *}$ & $(0.01)$ & 0.05 & $(0.01)$ \\
\hline$\sigma, \mathrm{St}=1$ & $0.03^{* * *}$ & $(0.00)$ & $0.03^{* * *}$ & $(0.00)$ & $0.05^{* * *}$ & $(0.00)$ & $0.05^{* * *}$ & $(0.01)$ & 0.02 & $(0.00)$ \\
\hline Log-Likelihood & 177.04 & & 213.44 & & 182.77 & & 148.14 & & 219.88 & \\
\hline
\end{tabular}

This table reports the estimation results for equation (11)-(15) with *,**,*** denoting the $10 \%, 5 \%$ and $1 \%$ significance levels.

Figure 2 shows conditional transition probabilities of the five groups of ETFs to be in state 1 (high volatility) at $t$ based on the set of information at time $t=1, P\left(S_{t}=1 \mid \Omega_{t-1} ; \theta\right)$, respectively. We also overlay these probabilities together with NBER business cycles. These probabilities are determined by the lagged values of conditioning information; therefore, they are reflections of investors' belief on the conditional likelihood of being in the high volatility state in the following period. In particular we see that during the 2000 Dot-com Bubble, ETFs with a focus on the technology industry stay in state 1 (high volatility) for a relatively long time. Also, for the 2008 Financial Crisis, ETFs with a focus on the financial industry suffer a big loss and persistently remain in state 1 (high volatility) until the end of sample period. From these evidences we can also identify the high volatility state as recession and the low volatility state as expansion. 

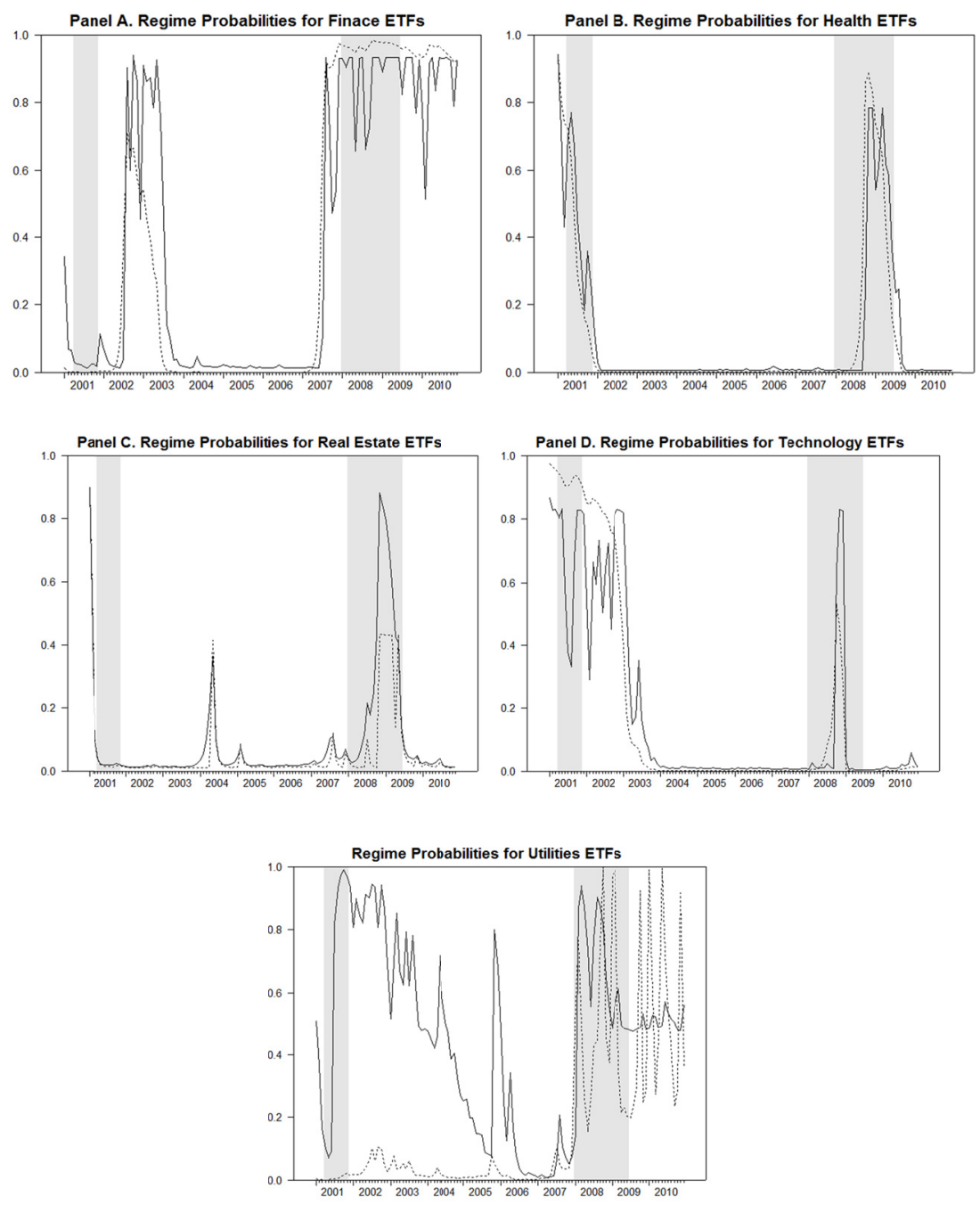

Figure 2. Regime Transition Probabilities

This figure shows regime -switching probabilities for each group of ETFs. The ex-ante probabilities are denoted is solid lines while smoothed probabilities are denoted by dotted one. Shadows are NBER recessions.

Table 3 suggests that for the five groups of ETFs the coefficients of the T-bill rate are all negative for state 1(high volatility). In particular, T-bill rate coefficients for ETFs with a focus on the financial industry and the health industry have a statistical significance of $1 \%$, while the coefficients for utility ETFs has a statistical significance of 5\%. In state 2 (low volatility) the T-bill rate coefficients remain negative for all five groups of ETFs, but much smaller in magnitude. This suggests that in state 1 (high volatility), the shocks of interest rates have larger impact on the performance of ETFs; however, in state 2 (low volatility) the performance of ETFs are not heavily impacted by these shocks. There are also systematic variations in the coefficients of the default risk premium. In state 1(high volatility), the five groups of ETFs all have positive coefficients on the default risk premium at the $1 \%$ significance level, except technology ETFs which are positive at the $10 \%$ level. These coefficients in our low volatility state are much smaller in magnitude. This indicates that the performances of ETFs are more affected by the default risk premium during volatile times. In particular, we see this effect is most pronounced for the group of ETFs with a focus on the financial industry, but less so for the utilities group. The coefficient for finance ETFs in state 1 is 9.68 with a standard deviation of 1.50 and the coefficient of utility ETFs is 4.18 with a standard deviation of 0.56 .

The coefficients for the change in money supply are only significant in state 1 for real estate and health ETFs. The positive sign of these coefficients suggests that better expected performance of ETFs focusing on real estate is associated with higher growth in the money supply. This makes sense since the Federal Reserve is more likely 
to increase money supply in bad economic conditions. The predictive power for the changes in the growth of industrial production, however, is limited under our specification. Lastly, the coefficient on the dividend yield is significant for ETFs with a focus in the health and technology industries in both the high and low volatility states. In addition they are positive and significant for finance ETFs in the low volatility state and positive and significant for utility ETFs in the high volatility state.

Our results so far indicate that the predictive power of these macro variables depends both on the underlying volatility state and the focus of the ETF. Moreover, ETFs have asymmetric risk exposure across expansion and recession states. However, these results do not prove that the asymmetries are significant statistically. Therefore, a series of statistical tests are performed regarding the existence of the two states in the conditional mean and variance for each group of ETFs. When testing for asymmetry of the coefficients across the two states, one has to take consideration that regime-switching probabilities may not be well identified in the standard likelihood ratio test, as Hansen (1992) discusses. Therefore, the regression coefficients from the Markov regime-switching model are restricted by setting the coefficients equal to one another across the two states. The test statistic from this specification is a standard chi-squared distribution. Specifically, the following null hypotheses are tested: the regression coefficients for the T-bill rate, default risk premium, change in the money stock, growth of industrial production, as well as dividend yield are the same in magnitude across the two states for each group of ETFs. More formally, $\beta_{k, S_{t}=1}^{i}=\beta_{k, S_{t}=2}^{i}$, for $k=1, \ldots, 5$. Table 4 reports the results of the tests. The differences are statistically significant for ETFs with a focus on the financial industry, health industry and utilities industry, indicating that we reject the null hypothesis for these ETFs.

Table 4. Likelihood Ratio Test

\begin{tabular}{|c|c|c|c|c|c|}
\hline & $\begin{array}{l}\text { Finance } \\
\text { ETFs }\end{array}$ & $\begin{array}{l}\text { Health } \\
\text { ETFs }\end{array}$ & $\begin{array}{l}\text { Real Estate } \\
\text { ETFs }\end{array}$ & $\begin{array}{l}\text { Technology } \\
\text { ETFs }\end{array}$ & $\begin{array}{l}\text { Utilities } \\
\text { ETFs } \\
\end{array}$ \\
\hline Unrestricted Log-likelihood & 177.04 & 213.44 & 182.77 & 148.14 & 219.88 \\
\hline $\begin{array}{l}\text { Restricted Log-likelihood } \\
\text { with }\end{array}$ & 166.96 & 207.50 & 178.70 & 143.96 & 215.22 \\
\hline $\begin{array}{l}\beta_{r_{\mathrm{S}-1}}^{i}=\beta_{r \mathrm{c}-\mathrm{l}}^{i}, \text { for } k=1, \ldots, 5 \\
\mathrm{p} \text {-value }\end{array}$ & 0.00 & 0.04 & 0.15 & 0.14 & 0.09 \\
\hline
\end{tabular}

We conduct the likelihood ratio test for each group of ETFs. The null hypothesis is that regression coefficients are equal across regimes

\section{Conclusion}

This paper investigates the link between exchange-traded funds and the macro economy. Using a nonlinear approach, we find that the T-bill rate, default risk premium, change in the money supply, growth of industrial production, and dividend yield have predictive power for the return on exchange-traded funds. Moreover, the predictive power of these macro variables depends both on the underlying volatility state and the focus of the ETF. Additionally, our evidence suggests that ETFs have asymmetric risk exposure across expansion and recession states. The framework we use is flexible enough to be applied to the study of a variety of topics within financial economics. By incorporating regime-switching one may examine the time-varying nature of financial markets, making this a beneficial tool for empirical studies.

\section{References}

Ackert, L. F., \& Tian, Y. S. (2008). Arbitrage, Liquidity, and the Valuation of Exchange Traded Funds. Financial Markets, Institutions \& Instruments, 17(5), 331-362. http://dx.doi.org/10.1111/j.1468-0416.2008.00144.x

Campbell, J. Y. (1987). Stock Returns and the Term Structure. Journal of Financial Economics, 18, 373-399. http://dx.doi.org/10.1016/0304-405X(87)90045-6

Cherry, J. (2004). The Limits of Arbitrage: Evidence from Exchange Traded Funds. Working Paper. University of Michigan at Ann Arbor. http://dx.doi.org/10.2139/ssrn.628061

Dellva, W. L. (2001). Exchange-Traded Funds Not for Everyone. Journal of Financial Planning, 14(4), 110-24.

Engle, R. F., \& Sarkar, D. (2002). Pricing Exchange Traded Funds. Working Paper, S-DRP-02-11, New York University.

Fama, E. F. (1981). Stock Returns, Real Activity, Inflation, and Money. American Economic Review, 71, 545-565. 
Filardo, A. J. (1994). Business Cycle Phases and Their Transitional Dynamics. Journal of Business and Economic Statistics, 12, 299-308. http://dx.doi.org/10.2307/1392086

Gallagher, D. R., \& Segara, R. (2005). The Performance and Trading Characteristics of Exchange-traded Funds. Working Paper. The University of New South Wales.

Gray, S. F. (1996). Modeling the Conditional Distribution of Interest Rates as a Regime Switching Process. Journal of Financial Economics, 42, 27-62. http://dx.doi.org/10.1016/0304-405X(96)00875-6

Gulen, H., Xing, Y., \& Zhang, L. (2011). Value Versus Growth: Time-Varying Expected Stock Returns. Financial Management, 40(2), 381-407.

Jares, T. E., \& Lavin, A. M. (2004). Predictable Pricing Errors and Fair Value Pricing of US-based International Mutual Funds. Journal of Financial Regulation and Compliance, 12(2), 132-150. http://dx.doi.org/10.1108/13581980410810759

Kostovetsky, L. (2003). Index Mutual Funds and Exchange-Traded Funds. Journal of Portfolio Management, 29(4), 80-92. http://dx.doi.org/10.3905/jpm.2003.319897

Lin, C. C., Chan, S. J., \& Hsu, H. (2006). Pricing Efficiency of Exchange Traded Funds in Taiwan. Journal of Asset Management, 7(1), 60-68. http://dx.doi.org/10.1057/palgrave.jam.2240202

Madura, J., \& Richie, N. (2004). Overreaction of Exchange-Traded Funds during the Bubble of 1998-2002. Journal of Behavioral Finance, 5(2), 91-104. http://dx.doi.org/10.1207/s15427579jpfm0502_3

Perez-Quiros, G., \& Timmermann, A. (2000). Firm Size and Cyclical Variations in Stock Returns. Journal of Finance, 55, 1229-1262. http://dx.doi.org/10.1111/0022-1082.00246

Poterba, J. M., \& Shoven, J. B. (2002). Exchange Traded Funds: a New Investment Option for Taxable Investors. Working Paper. NBER.

\section{Notes}

Note 1. Gulen, Xing and Zhang (2011) study time variations of the expected value premium using a two-state Markov-switching model. They find that when conditional volatilities are high the expected excess returns of value stocks are more sensitive to aggregate economic conditions than the expected excess returns of growth stocks. As a result, the expected value premium is time varying, with the value premium tending to spike upward in the high volatility state only to decline more gradually in subsequent periods.

Note 2. Perez-Quiros and Timmermann (2000) adopt a flexible two-state regime-switching model to analyze the presence of asymmetries in the variation of small and large firm risk over the economic cycle. Their model shows that small firms display the highest degree of asymmetry in their risk across recession and expansion states. This translates into a higher sensitivity of these firms' expected stock returns with respect to variables that measure credit market conditions.

Note 3. Maximum Likelihood Estimation

Note 4. A complete list of the ETFs that are included in our sample is available upon request.

Note 5. The Center for Research in Security Prices 